\title{
Safety Culture in Digital Fabrication: Perceptions, Model and Co-Creation Approach
}

\author{
Dorina Rajanen \\ University of Oulu \\ Mikko Rajanen \\ University of Oulu
}

We describe a participatory approach for involving digital fabrication stakeholders in a co-creation exercise focused on promoting, adopting, and developing safety culture in digital fabrication. Participants shared their perceptions of safety in digital fabrication and engaged in the ideation, design, and prototyping of instructional storyboards for promoting safety in digital fabrication. We also describe a conceptual model of safety culture in digital fabrication built upon three principles, namely professional, social, and environmental responsibilities. We reflect on how the co-creation approach can contribute to adopting a safety culture in digital fabrication through the mediating roles of social and experiential learning.

Keywords: digital fabrication, safety culture, co-creation, participatory media, instructional design, experiential learning, social learning, professional responsibility, social responsibility, environmental responsibility, organizational culture

\section{INTRODUCTION}

Digital fabrication is a new manufacturing paradigm for business, community, or personal projects. Information and communication technologies' advancements make possible to create novel, high-quality, and personalized designs that can be produced locally and at a low cost. Moreover, digital fabrication became an effective tool to learn science, technology, and design disciplines because it provides hands-on experience of abstract concepts that are otherwise difficult to understand.

Typically, a fabrication process involves four phases of product development (design, manufacturing, use, and disposal) to ensure the product is produced and used in the best way in and for society (Chen et al., 2015). In established production settings, there are strict standards, rules, and laws that govern the production process to ensure that the safety and quality standards are met. The product development has also different sustainability indicators which need to be considered because the production process will eventually somehow affect the society (Chen et al., 2015).

Among the quality and sustainability dimensions that are important in manufacturing across industries, but also in public services, safety is one factor that must be considered (see e.g., Chen et al., 2015; Gibson et al., 2015). Safety is a multidimensional concept, which includes minimizing the risks of accidents and damages, as well as maximizing the well-being in professional work for example by improving the ergonomics of work and human-technology interaction. The Industrial Revolution and the invention of 
steam engine in $18^{\text {th }}$ century led to workplace safety concerns and started the efforts to minimize safety risks at workplace through regulations, safer equipment, and safety management. However, safety issues are on the one hand difficult to communicate and enforce, and on the other hand easy to overlook in various professional settings (see e.g., Baram \& Schoebel, 2007).

To address the challenge of communicating and complying with safety issues in a digital fabrication context, we have designed, organized, and facilitated a workshop. With this approach we generally aimed at 1) exploring effective ways to communicate safety issues, and 2) developing a safety culture among makers in their different roles as students, teachers, educators, designers, producers, academics. The workshop was organized in May 2019 as part of the FabLearn Europe Conference in Oulu, Finland (see Rajanen \& Rajanen, 2019a). During the workshop, we engaged the participants into sharing their views and experiences on safety culture in digital fabrication contexts including makerspaces, fab labs, and personal fabrication. Furthermore, we organized a co-creation exercise for developing an instructional safety video through ideating, designing, and prototyping a storyboard. The outcome of the workshop in terms of storyboards is published in the INTERACT series (Rajanen \& Rajanen, 2020). In this paper, we describe the workshop and the participants' perceptions of safety issues in digital fabrication. Furthermore, we reflect on how co-creation can contribute to adopting a safety culture in digital fabrication. For this reflection, we employ a conceptual model of safety culture described in an earlier paper (Rajanen \& Rajanen, 2019b) and summarized briefly here as consisting of three dimensions or principles namely, social responsibility, professional responsibility, and environmental responsibility.

The paper is organized as follows. In the next section, we outline the issues of safety culture in digital fabrication. In section three, we present the conceptual model of safety culture in digital fabrication. Section four introduces the safety co-creation workshop, describes the participants and their perceptions of safety in digital fabrication, and the process followed in the co-creation exercise. Section five discusses the findings and reflects on the co-creation activities as enablers of safety culture. Section six concludes the paper.

\section{SAFETY CULTURE IN DIGITAL FABRICATION}

Digital fabrication involves various rapid prototyping techniques and technologies such as 3D printing and laser cutting. These machines require adequate training and supervision to be used safely. Each equipment comes with instruction manuals, safety guidelines, and safety material data sheets that are incorporated in the laboratory safety policies. Safety issues related to digital fabrication include hazards to humans, machines, and environment. Safety issues originate from incorrect use of equipment, omitting personal protection equipment, using wrong materials, poor waste management, and not adopting chemical hygienic practices in the lab (see e.g., Kohtala \& Hyysalo, 2015; Short et al., 2015). Typically, makerspaces and fabrication labs provide training on safety practices, as well as different instructional materials on various media such as wikis, videos, warning signs, and posters. However, the safety practices may differ from organization to organization (see e.g., Baram \& Schoebel, 2007), while the literature documenting how sustainability, safety, and risks are actually managed in makerspaces and fabrication labs is very scarce (Kohtala \& Hyysalo, 2015). Moreover, generally safety is a difficult topic to communicate and very challenging to implement correctly in an organization, especially one defined by the particularities of makerspaces and fab labs where majority (or many of the) users, makers, and visitors come from the general public, are heterogeneous in terms of demographics, and use the equipment on a voluntary basis and not part of a regular and monitored program. Thus, this paper builds on our previous work on the topic (Rajanen \& Rajanen, 2019a,b) to fill a gap in the literature addressing the concept of safety culture in digital fabrication and to provide both researchers and practitioners in digital fabrication guidance in understanding and adopting the safety culture.

The safety culture concept originated after the Chernobyl accident to incorporate both safety management issues (technical attention to hazards, deployment of operational procedures, regulatory compliance programs) and organizational and individual safety mindsets (Baram \& Schoebel, 2007; Hudson, 2007). The latter include principles of leadership and value-sharing, enhanced communications 
and organizational learning, and knowledge about the factors which shape individual and group behaviors (Baram \& Schoebel, 2007).

Though the concept of safety culture is very important in industry (Gordon et al., 2007; Zhou et al., 2012), there are a lot of variations on how this concept is defined, understood, and applied in practice (Baram \& Schoebel, 2007). For example, in the design and research domain, safety culture focusses on understanding and preventing risks that users of a design may face in future (Gordon et al., 2007). In healthcare, safety culture refers to risks to both personnel and patients (Flin, 2007). Furthermore, safety is also related to social and environmental sustainability, for example in production settings when a product development can have long-term impact on society and environment (Chen et al., 2015).

Typically, the safety culture is assessed through surveys that measure the safety climate in an organization (see e.g., Flin, 2007; Ostrom et al., 1993) or through safety culture maturity models to indicate a progress from 'emerging' to 'continually improving' safety culture (Gordon et al., 2007). As an organizational culture issue, safety culture deals with defining and adopting a safety behavior within that organization. Furthermore, after the initial creation of a safety culture in an organization, the safety culture has to be actively maintained. Many high profile accidents have been attributed to safety culture not being actively maintained in the organization and the safe practices being ignored as a result (e.g. Apollo 1 and the space shuttle accidents as a result of NASA starting to cut corners in their safety practices and procedures).

Generally, digital fabrication is safer than traditional fabrication techniques (Zhou et al., 2012), however there are concerns about the toxicity of the materials and the sustained exposure to harmful substances that result from the use of digital fabrication and rapid prototyping processes that may negatively impact health and environment in short and long run (Chan et al., 2018; Kohtala \& Hyysalo, 2015; Short et al., 2015; Väisänen et al., 2018). These issues should be dealt with by designing the workspaces using occupational health standards (Väisänen et al., 2018). Moreover, other safety issues can be managed by adequate training, correct use of fabrication equipment and personal protection equipment, proper waste management, and adopting adequate chemical hygienic practices in the lab (including regular hand-washing and keeping the space clean)

For digital fabrication projects in open makerspaces and fab labs, safety culture translates into defining and adopting by both staff and makers of safety rules for using the space, the equipment, materials, for waste disposal, and for chemical hygiene. These general aspects include social interactions with the staff and other makers, responsibilities to keep the space clean, training, reporting of safety issues, optimizing the use of materials, supervising the fabrication process. Safety culture is achieved best by employing a participatory approach where all stakeholders are involved in developing the safety culture (Baram \& Schoebel, 2007). However, as the digital fabrication is rapid, iterative, and hacking-oriented field by nature and being usually open to all enthusiasts, the challenge is how to make fabricators with different backgrounds and expectations to adopt the correct safety behavior in the lab and beyond. This involves different iterative and incremental stages such as communicating and motivating the safety issues, providing an effective training to all fabricators, and creating a safety culture.

\section{CONCEPTUAL MODEL OF SAFETY CULTURE IN DIGITAL FABRICATION}

The challenge in adopting a correct safety behavior in makerspaces or fab labs lies in the particularities of the cultural and organizational context of digital fabrication. It can be difficult to define and implement a safety culture especially when the organization within which digital fabrication projects develop is open for public or non-professionals such as in makerspaces and fabrication laboratories. In these spaces, makers can come from various professional, social, and cultural backgrounds and their level of involvement in the product design and development varies, as well as their usage patterns and interests regarding the digital fabrication spaces and equipment. Thus, the makers' adoption of a desired organizational safety behavior is not as straightforward as in traditional industrial settings with contractual employment obligations and strong established focus on safety as part of professionalism.

Journal of Higher Education Theory and Practice Vol. 20(14) 2020219 
From the perspective of safety behavior, in an earlier paper (Rajanen \& Rajanen, 2019b), we proposed three dimensions that can contribute to the understanding and adoption of the safety culture in an organizational context such as open makerspaces and fab labs. These dimensions are demarcated as being the professional, social, and environmental responsibilities (in short, the 3R model of safety culture; see Figure 1) and we believe that they can act as extrinsic or intrinsic motivators for adopting a safety behavior depending on the individual values and beliefs. These dimensions or principles are briefly described in the following.

\section{FIGURE 1}

\section{CONCEPTUAL MODEL OF DEFINING SAFETY CULTURE IN DIGITAL FABRICATION}

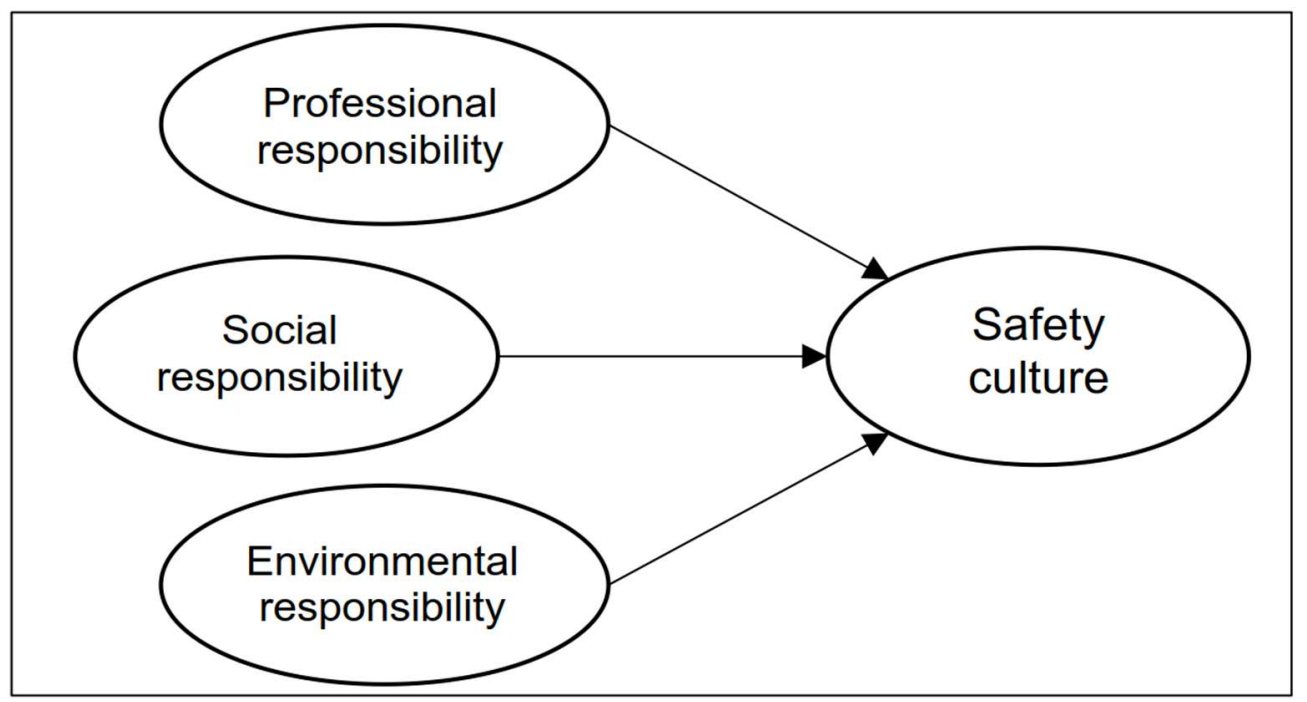

\section{Safety as Professional Responsibility}

The concept of safety as a professional responsibility integrates the safety awareness and risk management as cultural norms in the organization (Sellers, 2014). According to this principle, stakeholders at all levels of the professional organization (e.g., workers, managers, professionals) are responsible for improving and maintaining the common safety culture (Sellers, 2014). Accordingly, the safety performance and improvement are key performance indicators at both organizational and individual level, and the safety issues must be treated with respect (Sellers, 2014). In this concept, the safety consciousness, concerns and compliance are part of the professionalism, and an integral part of personal professional responsibility towards oneself, towards the colleagues and other stakeholders, and towards the society in general (Sellers, 2014). Aviation, space, and nuclear industries are examples of professional fields, where defining, following, and improving the safety procedures form the basis of professional practice and where safety awareness is a cultural norm and a form of professional empowerment. In these fields, one cannot become a professional or maintain their status as a professional, unless they follow the safety guidelines, safe operational procedures, and have a proactive safety mindset. Safety is seen in these fields as a continuous process of constant improvement and the responsibility of all professionals in the field.

Furthermore, the professional responsibility principle is based on the definition that a professional in any field follows a regulated set of professional behavioral standards that are embodied in a commonly accepted professional code of conduct (Patrucco et al., 2010). Thus, according to this principle it is expected that makers in digital fabrication adopt and improve a professionally responsible conduct in the fab lab or makerspace, which includes learning and complying with the rules, norms and standards related to safety. The makers should be regarded and self-identified as qualified and professional makers, who as professionals follow the safety rules and consider safety consciousness and concerns, as well as continuous 
safety improvements as part of professionalism and professional responsibility towards oneself, peers, others, and the society.

\section{Safety as Social Responsibility}

Organizational social responsibility has been defined as the voluntary integration of social concerns and issues into the organizational decision-making (Chen et al., 2015). This voluntary adherence to social concerns can occur as a result of different determinants such as: the prospects of using the social responsibility as a competitive advantage in marketing, genuine concerns for the societal impact of organizational operations, or fears of governmental regulations in the absence of effective self-regulation. The social concerns address the general working conditions, the impact of work on the long-term health of the stakeholders and stakeholder empowerment (Chen et al., 2015), and sustainability concerns such as monitoring and displaying the energy consumption (Kohtala \& Hyysalo, 2015).

In digital fabrication spaces, the social dimension of safety includes ensuring that the digital fabrication space itself is free of hazards, and that the well-being, long-term health, safety, and empowerment of makers and staff are carefully considered (see e.g., Chen et al., 2015). This means that the operation of machines and materials is done minimizing the risk of hazards and impact on short-term or long-term safety and health of staff and makers. The staff and the makers as stakeholders should be empowered to influence and develop the safety culture including practices and artefacts in the makerspace or fab lab. Integrating social responsibility into digital fabrication would also mean to participate in co-creation activities for increasing awareness, concern, and responsibility towards safety issues. Other activities to adhere to safety practices as social responsibility can involve makers to contribute at designing for safety, at monitoring and keeping to a minimum the levels of harmful particles, gases, substances, and noise (see Zhou et al., 2012 for an example from construction industry).

\section{Safety as Environmental Responsibility}

Organizational environmental responsibility has been defined as the voluntary integration of environmental thinking into the organizational decision-making (Chen et al., 2015). Similarly with the social responsibility, the voluntary integration of ecological thinking can be driven by various factors such as: using environmental responsibility as a marketing strategy, genuine concerns for the environment, or fears of governmental intervention by regulations on waste and pollution if the industry does not selfregulate itself. Environmental responsibility manifests in organizations as safe disposal of hazardous waste (Short et al., 2015), minimizing the energy consumption and monitoring it (Chen et al., 2015; Kohtala \& Hyysalo, 2015), managing the impact of the process on climate change and environment (Chen et al., 2015).

In digital fabrication, safety as environmental responsibility includes optimizing the use of materials, consumables and energy, preferring renewable materials, minimizing the waste, recycling the waste when possible, and disposing the hazardous waste safely. Also providing and adopting means to collaborate and participate in raising awareness, concern, and responsibility towards how digital fabrication process impact environment and climate change contribute to enhancing safety culture through environment responsibility.

\section{Summary}

In summary, the proposed conceptual model predicts that the three types of responsibilities, professional, social, and environmental shape the individual and organizational safety behavior and culture. These three principles rely on specific values towards performance, users and society, and environment, respectively (Rajanen \& Rajanen, 2019b). We recommend that communication approaches and participatory practices can be employed to communicate these types of responsibilities and values to makers in order to create and activate extrinsic and intrinsic motivations of adopting the target safety behavior. Participatory and collaborative approaches are recommended in the literature as providing effective results in raising awareness, concern, and responsibility (see e.g., Baram \& Schoebel, 2007; Patrucco et al., 2010). To explore the possibilities of using participatory communication approaches in shaping a safety culture in digital fabrication, we have designed, organized and facilitated a workshop that centered around a cocreation exercise. The workshop built on the assumption that the adoption of the safety conduct will be 
achieved progressively through experiential and social learning (see Bandura, 1977; Hawtrey, 2007). The workshop is presented in the next section.

\section{THE WORKSHOP}

The workshop was held at the University of Oulu, Tellus Stage on 28 May 2019. It was motivated by, on one hand, the increased interest in digital fabrication in fab labs, maker spaces, libraries, and schools and, on the other hand, the needs for considering safety issues when using digital fabrication equipment and laboratory spaces open for public and non-professional users. The aims of the workshop were manifold, namely: to increase awareness of safety issues in digital fabrication, to promote a safety culture in digital fabrication towards its adoption and development, to discuss and share experiences and information about safety in digital fabrication, and to ideate, design, and prototype storyboards for an instructional video presenting digital fabrication safety rules. For the last aim, a co-creation activity was planned and conducted. Moreover, the workshop was a means to explore the feasibility and effectiveness of using participatory communication approaches to shape the safety culture in digital fabrication.

Thus, the workshop method (Ørngreen \& Levinsen, 2017) was employed both as a research method to gather knowledge about how safety culture in digital fabrication is viewed by participants, and as a means to achieve the goal of the co-creation exercise, namely increasing awareness of, promoting, and contributing to developing the safety culture through participatory practice. The workshop was conducted following the guidelines of research ethics and participants have provided their informed consent by signing a written informed consent form (see Rajanen \& Rajanen, 2020).

Nineteen participants with various backgrounds and interests in digital fabrication, maker culture, digital fabrication education, and safety took part in the workshop. Eighteen of them have been actively involved in the co-creation of the instructional storyboards, while 2 facilitators have planned, organized and guided the activities. In total 4 storyboards have been created, each one for a different safety rule chosen by the participants out of 9 pre-defined rules. An overview of the workshop is presented in this paper along with the post-workshop insights. The informal feedback received from participants post-workshop was very positive and the storyboards can be used further in video production. The obtained sketches and storyboards are available via an open access publication (Rajanen \& Rajanen, 2020).

The workshop integrated the participatory philosophy with the principles of social learning, namely exposure to alternative views, collaborative learning, and adaptive learning (Biedenweg \& Monroe, 2013) and principles of experiential learning where participants carry out hand-on tasks and explorations, reflect upon them, develop their own abstractions and apply them further on in the real world (Hawtrey, 2007; Kolb et al., 2001). Thus, the co-creation exercise relied on communication and design methods and theories that are 'human-centered', such as the mentioned experiential and social learning techniques, but also cocreation, user-centered and participatory design (Sanders, 2003), participatory media (Harris, 2014; Rheingold, 2008), framing theory (Entman, 1993), and visual rhetoric (Walsh, 2015). In this respect, during the workshop, participants were engaged several times to share their experiences and understanding of safety in digital fabrication, and collaborated in teams for ideating, designing, and prototyping a storyboard for an instructional safety video presentation.

The workshop lasted 2 hours and consisted of the following steps:

1. Presentation of workshop facilitators and participants (ca. $10 \mathrm{~min}$ ),

2. Introduction to safety in digital fabrication (10 min),

3. Sharing of experiences of and views on safety issues in digital fabrication (ca. $25 \mathrm{~min}$ ),

4. Introduction to participatory video making with focus on storyboard co-creation (10 $\mathrm{min})$,

5. Short break to form the working groups (10 $\mathrm{min})$,

6. Group work ( $30 \mathrm{~min}$ ) including the selection of one safety issue to be presented in a storyboard, and the ideation, design, and prototyping of the storyboard,

7. Presentation of the storyboard to the workshop participants (10 $\mathrm{min})$,

8. Feedback, discussion and evaluation $(10 \mathrm{~min})$,

9. Conclusions (5 $\mathrm{min})$ 
Social and experiential learning were facilitated throughout the workshop. For example, at steps 1 and 3 everybody presented their background, interest, and experiences related to safety culture and digital fabrication using snowball and group discussion techniques. The informational content of the workshop at steps 2 and 4 was framed such that to include organizational and individual perspectives that can represent models for the participants. The group work required participants to work collaboratively, but also to apply safety concepts in practice in a hand-on exercise of drawing and storyboarding, thus both social and experiential learning were activated. Furthermore, the ideation, sketching and storyboarding exercise demanded users to map the safety concepts to both one's own everyday experiences and the digital fabrication context.

\section{Participants' Perceptions of Safety Issues}

Nineteen people enrolled to the workshop voluntarily, as part of the conference program. Participants (11 women, 8 men) were from Finland (9), Denmark (3), Belgium (2), Norway (1), Germany (1), Portugal (1) and Brazil (1), while one did not disclose the country. About half were from academia (PhD students, researchers, professors, and lecturers; 9) and the others were school teachers (4), and professionals with leading or advisory roles in national or local organizations (4); 2 did not disclose their occupation. Their fab lab roles were mainly of professional interest (teaching and instructing, managing a fab lab, studying, researching, networking and facilitating activities), but also making and designing.

A short questionnaire was administered, asking participants two questions about their views on and experiences of safety issues in digital fabrication (see Table 1). Furthermore, seven participants showed an intention to participate in a further study regarding the topic of safety culture.

TABLE 1

PERCEPTIONS OF SAFETY IN DIGITAL FABRICATION

\begin{tabular}{|l|l|l|l|l|l|}
\hline Question & M & SD & Min & Max & Median \\
\hline Importance of safety ${ }^{1}$ & 8.68 & 1.67 & 4 & 10 & 9 \\
\hline Safety culture adoption & Notes: 1: How important do you think is safety culture in digital fabrication? (Scale 0 Not important at all-10 Very \\
Nimportant); 2: What is the level of adoption of safety culture in digital fabrication currently based on your own \\
experience? (Scale 0 It is non-existent - 10 Continually improving or mature safety culture).
\end{tabular}

Generally, participants considered safety as an important or very important issue, rating it with the mean score of 8.68 out of 10 (see Table $1 \&$ Figure 2). A few participants were, however, moderate in their assessment. Examining the occupational profile, it was seen that generally people directly involved with fab labs had assessed the importance with the highest score, namely 10 . However, two in this group rated the importance with the score 8 . On the other hand, the lower scores were recorded for people not directly involved with fab lab and making, namely two school teachers; while the score 4 was given by a person not disclosing their occupation or role in digital fabrication. In contrast, the participants rated the adoption of safety culture in digital fabrication with values between 3 and 10 , where the most frequent was 3 , the mean value 5.61 and median 5.5 (see Table $1 \&$ Figure 3).

\section{Co-creation of Instructional Storyboards}

Eighteen participants engaged in group work that included the selection of the safety issues to be presented in storyboards, and the ideation, design, and prototyping of the storyboard. The participants had to consider the following:

- What is the safety issue about?

- How to convey the importance of this safety issue?

The 18 participants formed 4 groups, each working on representing one safety rule in a storyboard. Figure 4 illustrates the safety rules that were selected by the 4 teams. 
Participants presented their creations within the workshop and short Q\&A sessions followed each presentation and after all presentations. Facilitators concluded the 2-hour workshop with general feedback remarks. An informal voting of the preferred storyboard was attempted, however, participants agreed that all outputs were interesting, meaningful and ingenious. The participants thought that all storyboards were equally valuable and that they could be used and integrated in one video series or multiple thematic video series.

FIGURE 2

RATINGS FOR IMPORTANCE OF SAFETY

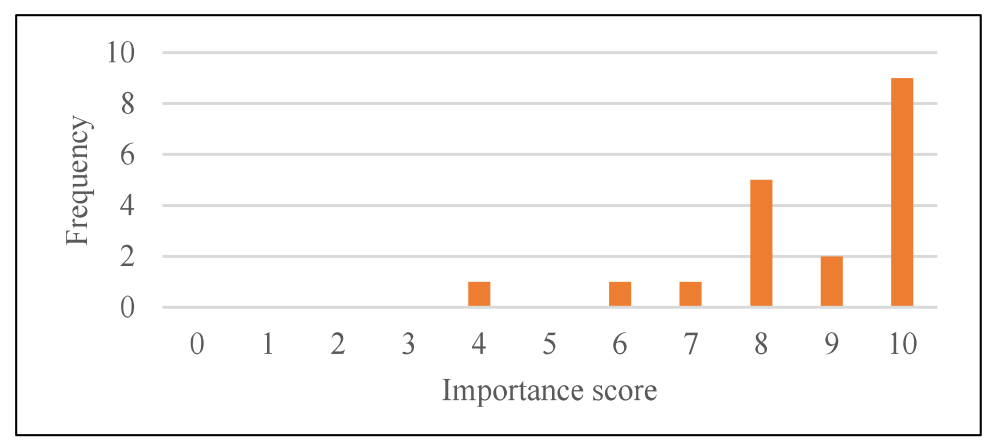

FIGURE 3

RATINGS FOR ADOPTION OF SAFETY CULTURE

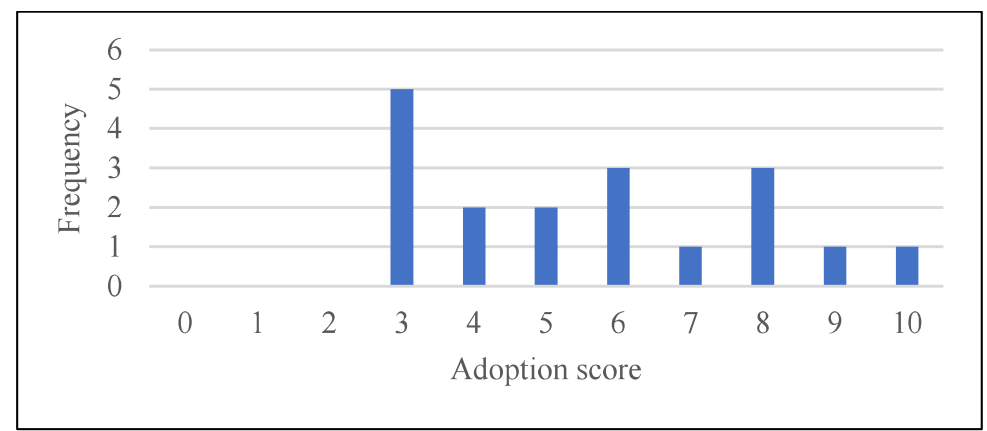




\section{FIGURE 4}

\section{SAFETY RULES CHOSEN FOR VIDEO STORYBOARDING}

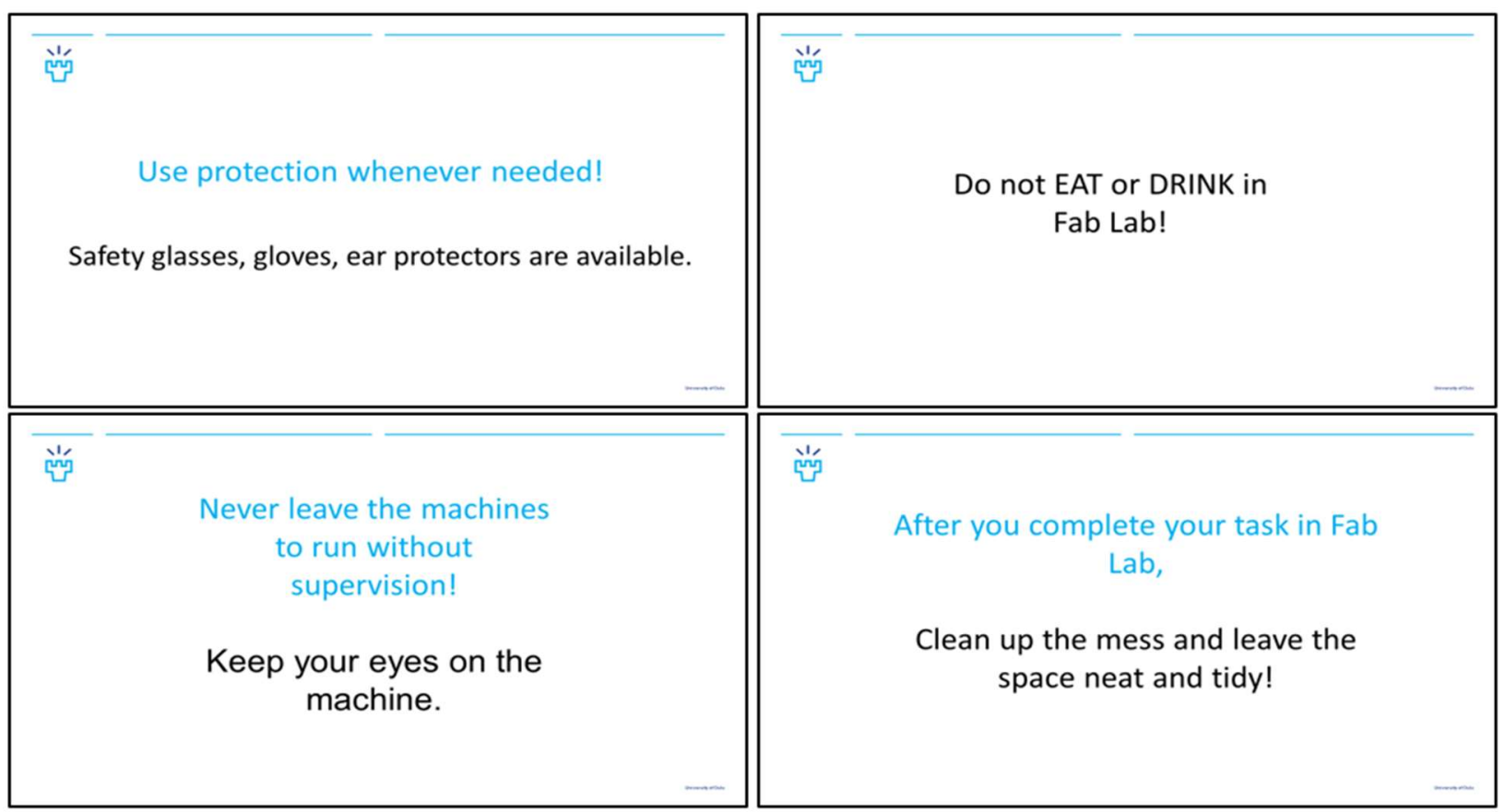

\section{DISCUSSION}

This study had a general two-fold aim: 1) to explore the feasibility and effectiveness of the workshop method for communicating safety issues, and 2) to increase awareness and adoption of safety culture in digital fabrication. We found that a 2-hour workshop is a feasible approach for the stated goals. The effectiveness was not measured formally, but the outcomes (storyboards), the enthusiasm of the participants, and the accomplishment of the tasks in the allocated time indicate that this method can be successfully employed both in conference settings (such as how this workshop was organized), but also in fab labs, makerspaces, and classrooms. Our workshop participants were highly educated adults, majority of them having professional backgrounds in the education and research domains. It is interesting for the future to carry out the workshop and examine the process and its outcomes with other type of public, including students, pupils, fab lab staff, and diverse groups such as those who regularly or occasionally visit fab labs and makerspaces.

We have inquired and assembled the participants' perceptions of safety culture in digital fabrication. We found that most of the participants considered safety issues as very important. The sample analyzed is relatively small and quite homogenous. However, the data revealed that it is likely that public not directly involved with fab lab equipment and work, such as school teachers, may be unaware of safety issues and importance. Moreover, future research should observe in more depth as well as in a larger sample the safety perceptions and behavior of fab lab staff as they play an important role in disseminating safety information and in elaborating a correct safety culture regarding the digital fabrication in their organization and society at large. The data regarding adoption of safety culture in digital fabrication indicated a rather low level of adoption; in particular, the fab lab managers in our sample quantified their general experiences with adoption as very low. The data shows that there are needed various actions to improve the current situation. For example, workshops, such as the one described in this paper, are one type of action towards this goal. This type of workshops could be organized regularly in fab labs and in school classrooms before visiting a fab lab or makerspace to increase awareness and to contribute to the development of a participatory safety culture. 
From a theoretical perspective, we formulated a conceptual model of safety culture consisting of three dimensions or principles: professional responsibility, social responsibility, and environmental responsibility (in short, the $3 \mathrm{R}$ model of safety culture). On one hand, workshops create the opportunity for experiential and social learning which rely on the principles of applying theoretical concepts in real life situations and adapting one's own existing views and experiences to new contexts and needs by reaching a broader perspective through interaction with others and applying existing mental structures to new, practical situations (see e.g., Biedenweg \& Monroe, 2013; Hawtrey, 2007; Kolb, 1984). On the other hand, the conceptual framework has the role to improve the understanding of safety behavior and to facilitate communication of and motivation towards adopting safety behavior and culture.

In the following, we apply the $3 \mathrm{R}$ model as a lens to examine the effectiveness of the participatory workshop and the co-creation exercise. In other words, we try to analyze whether and how the workshop and the co-creation activities have prompted the three responsibilities believed to drive a safety mindset, behavior, and culture. To do this, we map the steps in the workshop to the $3 \mathrm{R}$ dimensions and identify the mediating function of experiential and social learning features in this projection. Table 2 presents this mapping.

TABLE 2

MAPPING WORKSHOP ACTIVITIES TO 3R MODEL OF SAFETY CULTURE

\begin{tabular}{|c|c|c|}
\hline Workshop step & Experiential and Social learning & Safety culture driven by activating the $3 R s$ \\
\hline $\begin{array}{l}\text { 1. Presentation } \\
\text { of workshop } \\
\text { facilitators } \\
\text { and } \\
\text { participants }\end{array}$ & $\begin{array}{l}\text { Social learning and experiential } \\
\text { learning facilitated by social } \\
\text { interaction and connection between } \\
\text { participants and facilitators } \\
\text { (Biedenweg \& Monroe, 2013). }\end{array}$ & $\begin{array}{l}\text { Professional Responsibility: } \\
\text { - participants identify themselves as } \\
\text { stakeholders with own identity, role, and interest } \\
\text { in digital fabrication. } \\
\quad \text { - participants recognize the presence of a } \\
\text { larger community with shared but also varied } \\
\text { interests and backgrounds. } \\
\text { Social Responsibility: } \\
\text { - participants may recognize that as } \\
\text { background and interests in digital fabrication } \\
\text { vary among themselves there is a need to } \\
\text { consider them when being involved in digital } \\
\text { fabrication projects. }\end{array}$ \\
\hline $\begin{array}{ll}\text { 2. } & \text { Introduction } \\
\text { to safety in } \\
\text { digital } \\
\text { fabrication }\end{array}$ & $\begin{array}{l}\text { Social learning and experiential } \\
\text { learning facilitated by clarifying the } \\
\text { learning goals, providing } \\
\text { meaningful examples and situations } \\
\text { regarding safety issues and } \\
\text { organizational and individual } \\
\text { perspectives, as well as providing } \\
\text { resources and solutions (Biedenweg } \\
\& \text { Monroe, 2013; Schunk, 2012) } \\
\text { towards better communication of } \\
\text { safety in an organization. }\end{array}$ & $\begin{array}{l}\text { Professional Responsibility: } \\
\quad \text { - participants are exposed to information } \\
\text { presenting the history and importance of safety } \\
\text { and how this is addressed in other professional } \\
\text { fields such as aviation and construction. } \\
\quad \text { - safety is part of the professional conduct in } \\
\text { many fields including digital fabrication. } \\
\text { Social Responsibility \& Environmental } \\
\text { Responsibility: } \\
\quad \text { - participants are exposed to information on } \\
\text { risks and safety issues regarding social and } \\
\text { individual well-being and environmental } \\
\text { concerns in digital fabrication. }\end{array}$ \\
\hline $\begin{array}{l}\text { 3. Sharing the } \\
\text { experiences } \\
\text { of and views } \\
\text { on safety } \\
\text { issues in }\end{array}$ & $\begin{array}{l}\text { Social and experiential learning } \\
\text { facilitated by social interaction, } \\
\text { sharing /reflecting of experiences } \\
\text { and views, and active participation } \\
\text { in the discussion (Biedenweg \& }\end{array}$ & $\begin{array}{l}\text { Professional Responsibility: } \\
\quad \text { - participants act as stakeholders having own } \\
\text { experiences of and views on the issue, as well as } \\
\text { skills and mindsets that can bring novel and } \\
\text { valuable perspectives into the safety culture. }\end{array}$ \\
\hline
\end{tabular}




\begin{tabular}{|c|c|c|}
\hline Workshop step & Experiential and Social learning & Safety culture driven by activating the $3 R s$ \\
\hline $\begin{array}{l}\text { digital } \\
\text { fabrication }\end{array}$ & $\begin{array}{l}\text { Monroe, 2013; Hawtrey, 2007; } \\
\text { Schunk, 2012). }\end{array}$ & $\begin{array}{l}\text { Social Responsibility \& Environmental } \\
\text { Responsibility: } \\
\quad \text { - participants learn from others' experiences } \\
\text { and views and adapt their knowledge and views } \\
\text { on social and environmental responsibilities } \\
\text { accordingly. }\end{array}$ \\
\hline $\begin{array}{l}\text { 4. Introduction } \\
\text { to } \\
\text { participatory } \\
\text { video } \\
\text { making with } \\
\text { focus on } \\
\text { storyboard } \\
\text { co-creation }\end{array}$ & $\begin{array}{l}\text { Social and experiential learning } \\
\text { facilitated by providing resources } \\
\text { and guidance for skill development } \\
\& \text { knowledge acquisition (Hawtrey, } \\
\text { 2007; Schunk, 2012). }\end{array}$ & $\begin{array}{l}\text { Professional Responsibility: } \\
\quad \text { - participants are exposed to new } \\
\text { communication techniques such as video making } \\
\text { and video presentation and are acquainted with } \\
\text { ways to contribute to developing safety culture } \\
\text { for the team work as well as transferring this } \\
\text { knowledge in own organization/community, } \\
\quad \text { - participants are empowered to become } \\
\text { active stakeholders in the safety culture co- } \\
\text { creation. } \\
\text { Social Responsibility: } \\
\quad \text { - video making and video presentation are } \\
\text { accessible ways to communicate and participate, } \\
\text { which empower the makers and the community } \\
\text { to contribute at elaborating and adopting an } \\
\text { adequate safety culture. }\end{array}$ \\
\hline 5. Short break & - & 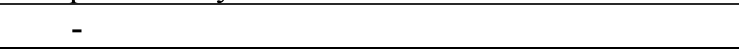 \\
\hline $\begin{array}{l}\text { 6. Group work } \\
\text { including the } \\
\text { selection of } \\
\text { one safety } \\
\text { issue to be } \\
\text { presented in } \\
\text { a storyboard, } \\
\text { and the } \\
\text { ideation, } \\
\text { design, and } \\
\text { prototyping } \\
\text { of the } \\
\text { storyboard }\end{array}$ & $\begin{array}{l}\text { Social and experiential learning } \\
\text { facilitated by social interaction, } \\
\text { sharing /reflecting of experiences } \\
\text { and views, and active participation } \\
\text { in the discussion and co-creation } \\
\text { (Biedenweg \& Monroe, 2013; } \\
\text { Hawtrey, 2007; Schunk, 2012). } \\
\text { Knowledge is constructed through } \\
\text { interaction with others and adapting } \\
\text { their conceptions (Postareff \& } \\
\text { Lindblom-Ylänne, 2008). Intrinsic } \\
\text { motivation and learnings goals are } \\
\text { attained by providing participants } \\
\text { with choices and opportunities } \\
\text { (Schunk, 2012). }\end{array}$ & $\begin{array}{l}\text { Professional Responsibility: } \\
\quad \text { - participants act as empowered } \\
\text { stakeholders; they prioritize and select the safety } \\
\text { issues that they consider most important or } \\
\text { relevant to their skills and experience, share their } \\
\text { views and experiences on the safety issues to co- } \\
\text { create a joint storyboard, utilize their personal } \\
\text { creativity and storytelling skills. } \\
\text { Social Responsibility \& Environmental } \\
\text { Responsibility: } \\
\quad \text { - participants learn from other's experiences } \\
\text { of and views on social and environmental factors } \\
\text { related to safety, and adapt their own views } \\
\text { accordingly to reach a consensus by co-creating a } \\
\text { joint storyboard on the selected safety issue. }\end{array}$ \\
\hline $\begin{array}{l}\text { 7. Presentation } \\
\text { of the } \\
\text { storyboard to } \\
\text { the } \\
\text { workshop } \\
\text { participants }\end{array}$ & $\begin{array}{l}\text { Social and experiential learning } \\
\text { facilitated by social interaction, } \\
\text { sharing /reflecting their creations, } \\
\text { the feeling of belonging to a group, } \\
\text { the feeling of being a stakeholder } \\
\text { and contributor (Biedenweg \& } \\
\text { Monroe, 2013; Hawtrey, 2007; } \\
\text { Schunk, 2012). Again, knowledge } \\
\text { is shaped by exposition to other } \\
\text { views and inter-group } \\
\text { communication (Postareff \& } \\
\text { Lindblom-Ylänne, 2008; Schunk, } \\
\text { 2012). }\end{array}$ & $\begin{array}{l}\text { Professional Responsibility: } \\
\quad \text { - participants act as empowered stakeholders } \\
\text { and professionals, sharing their safety } \\
\text { storyboards to other stakeholders present in the } \\
\text { workshop and to the digital fabrication } \\
\text { community in general. } \\
\text { Social Responsibility \& Environmental } \\
\text { Responsibility: } \\
\quad \text { - participants learn from other's storyboards } \\
\text { the emerging safety topics that are related to } \\
\text { social and environmental responsibilities. }\end{array}$ \\
\hline
\end{tabular}




\begin{tabular}{|c|c|c|}
\hline Workshop step & Experiential and Social learning & Safety culture driven by activating the $3 R s$ \\
\hline $\begin{array}{l}\text { 8. Feedback, } \\
\text { discussion } \\
\text { and } \\
\text { evaluation }\end{array}$ & $\begin{array}{l}\text { Social and experiential learning } \\
\text { facilitated by social interaction, } \\
\text { feedback and evaluation, } \\
\text { connection between participants } \\
\text { and facilitators and group identity } \\
\text { (Biedenweg \& Monroe, 2013; } \\
\text { Hawtrey, 2007; Schunk, 2012). } \\
\text { Again, knowledge is shaped by } \\
\text { exposition to other views and } \\
\text { communication among peers and } \\
\text { facilitators in the workshop } \\
\text { (Postareff \& Lindblom-Ylänne, } \\
\text { 2008; Schunk, 2012). }\end{array}$ & $\begin{array}{l}\text { Professional Responsibility: } \\
\quad \text { - participants act as empowered } \\
\text { stakeholders, giving and receiving feedback and } \\
\text { evaluating the storyboards of their professional } \\
\text { peers, forming a connection between workshop } \\
\text { participants and a group identity of co-creation of } \\
\text { safety culture in digital fabrication. } \\
\text { Social Responsibility \& Environmental } \\
\text { Responsibility: } \\
\quad \text { - participants give and receive feedback } \\
\text { about safety topics related to social and } \\
\text { environmental responsibilities. }\end{array}$ \\
\hline 9. Conclusions & $\begin{array}{l}\text { Social and experiential learning } \\
\text { facilitated by social interaction, } \\
\text { feedback and evaluation, } \\
\text { connection between participants } \\
\text { and facilitators and group identity } \\
\text { (Biedenweg \& Monroe, 2013; } \\
\text { Hawtrey, 2007; Schunk, 2012). }\end{array}$ & $\begin{array}{l}\text { Professional Responsibility: } \\
\text { - participants are encouraged to continue } \\
\text { acting as empowered professional stakeholders in } \\
\text { the future, sharing the safety ideas and practices } \\
\text { in their fab labs, makerspaces and other digital } \\
\text { fabrication spaces. } \\
\text { Social Responsibility \& Environmental } \\
\text { Responsibility: } \\
\text { - participants are encouraged to continue } \\
\text { taking into account the social and environmental } \\
\text { responsibilities in their practice in fab lab, } \\
\text { makerspace and other digital fabrication spaces. }\end{array}$ \\
\hline
\end{tabular}

Based on the theoretical examination of the workshop activities and their influence on participants, we can conclude that the workshop achieved its intended aims and the activities in the workshop potentially prompted the three types of responsibilities: professional, social and environmental.

To advance further this work and area of research and practice, we make the following recommendations to researchers and practitioners who are involved in developing the safety culture in digital fabrication using the participatory approach. Thus, whenever possible, complement the co-creation approach with the following actions:

1) Evaluate formally the meaningfulness of the learning from the learner perspective (c.f. Schunk, 2012).

2) Evaluate formally the learning from the $3 \mathrm{R}$ model perspective in order to identify to what extent the workshop and co-creation aligned to each of these three responsibilities.

3) Develop scales for measuring the $3 \mathrm{R}$ model and validate them.

4) Evaluate formally the extent to which the co-creation approach increases the safety culture awareness and adoption in the long run.

5) Include in the workshops hands-on training and exercises on video making to proceed with making a safety video based on the created storyboards, when time allows.

6) Conduct separate workshops on safety culture co-creation using storyboarding and video making, whenever possible.

7) Share the storyboards for later use between participants and the digital fabrication community in a similar way that the plans, code, and designs are shared in digital fabrication community.

\section{CONCLUSIONS}

This paper described a participatory approach for involving digital fabrication stakeholders in a cocreation exercise focused on promoting, adopting, and developing a safety culture in digital fabrication. 
The general aim of the study was two-fold: 1) to explore the feasibility and effectiveness of the workshop method for communicating safety issues, and 2) to increase awareness and adoption of safety culture in digital fabrication through the participatory workshop and co-creation. The workshop was successful as a communication and engagement method and can be replicated and developed further as part of the safety culture and practice. The co-creation approach is meant to be carried out with participants working within or interested in the digital fabrication field (students, teachers, practitioners, technologists, designers, academics, etc.). We believe that the workshop had an educating function and contributed to increasing and disseminating knowledge about safety in digital fabrication, and, thus, added the first brick at the construction of a safety culture in digital fabrication. During the workshop, the participants shared information and their experiences about safety in digital fabrication. While they considered safety as a very important issue in digital fabrication, they recognized that the adoption of safety culture is relatively low currently. Participants were engaged in the ideation, design, and prototyping of storyboards for promoting safety in digital fabrication during a co-creation exercise. The co-creation exercise was completed within the time allocated and resulted in four storyboards created by the teams. The paper also reflected the workshop experiences and learning situations in terms of three responsibilities' model. This model helps in understanding and shaping the safety culture by referring to three important principles: professional, social, and environmental responsibilities. Based on our understanding, the workshop and co-creation activities have prompted the three responsibilities. We believe that the three dimensions of safety culture and the cocreation workshop format can be useful for practitioners and researchers who are interested in creating, adopting, and maintaining safer digital fabrication. Furthermore, we provided some recommendations for future work on how the conceptual model as well as the co-creation participatory approach can be further evaluated and examined in other settings.

\section{ACKNOWLEDGEMENTS}

We thank all workshop participants for their participation and contributions.

\section{REFERENCES}

Bandura, A. (1977). Social Learning Theory. General Learning Press, New York.

Baram, M., \& Schoebel, M. (2007). Safety culture and behavioural change at the workplace. Editorial. Safety Science, 45(6), 631-636.

Biedenweg, K., \& Monroe, M. (2013). Teasing apart the details: How social learning can affect collective action in the Bolivian Amazon. Human Ecology, 41(2), 239-253.

Chan, F.L., House, R., Kudla, I., Lipszyc, J.C., Rajaram, N., \& Tarlo, S.M. (2018). Health survey of employees regularly using 3D printers. Occupational Medicine, 68(3), 211-214.

Chen, D., Heyer, S., Ibbotson, S., Salonitis, K., Steingrímsson, J.G., \& Thiede, S. (2015, November). Direct digital manufacturing: Definition, evolution, and sustainability implications. Journal of Cleaner Production, 107, 615-625.

Entman, R.M. (1993). Framing: Toward clarification of a fractured paradigm. Journal of Communication, 43(4), 51-58.

Flin, R. (2007). Measuring safety culture in healthcare: A case for accurate diagnosis. Safety Science, 45(6), 653-667.

Gibson, I., Rosen, D.W., \& Stucker, B. (2015). Additive Manufacturing Technologies: 3D Printing, Rapid Prototyping, and Direct Digital Manufacturing (2nd edition). New York: Springer.

Gordon, R., Kirwan, B., \& Perrin, E. (2007). Measuring safety culture in a research and development centre: A comparison of two methods in the air traffic management domain. Safety Science, 45(6), 669-695.

Harris, U.S. (2014). Communicating climate change in the Pacific using a bottom-up approach. Pacific Journalism Review: Te Koakoa, 20(2), 77-95. 
Hawtrey, K. (2007). Using experiential learning techniques. The Journal of Economic Education, 38(2), 143-152.

Hudson, P. (2007). Implementing a safety culture in a major multi-national. Safety Science, 45(6), 697722.

Kohtala, C., \& Hyysalo, S. (2015, July). Anticipated environmental sustainability of personal fabrication. Journal of Cleaner Production, 99, 333-344.

Kolb, D.A. (1984). Experiential Learning: Experience as a Source of Learning and Development. Englewood Cliffs, NY: Prentice-Hall.

Kolb, D.A., Boyatzis, R.E., \& Mainemelis, C. (2001). Experiential learning theory: Previous research and new directions. Perspectives on Thinking, Learning, and Cognitive Styles, 1(8), 227-247.

Ostrom, L., Wilhelmsen, C., \& Kaplan, B. (1993). Assessing safety culture. Nuclear Safety, 34(2), 163172.

Ørngreen, R., \& Levinsen, K. (2017). Workshops as a research methodology. Journal of E-learning, 15(1), 70-81.

Patrucco, M., Bersano, D., Cigna, C., \& Fissore, F. (2010). Computer image generation for job simulation: An effective approach to occupational Risk Analysis. Safety Science, 48(4), 508-516.

Postareff, L., \& Lindblom-Ylänne, S. (2008). Variation in teachers' descriptions of teaching: Broadening the understanding of teaching in higher education. Learning and Instruction, 18(2), 109-120.

Rajanen, D., \& Rajanen, M. (2019a). Co-creation of safety culture in digital fabrication. In Proceedings of FabLearn Europe 2019 Conference, Finland. ACM. https://doi.org/10.1145/3335055.3335077

Rajanen, D., \& Rajanen, M. (2019b). Safety culture in digital fabrication: Professional, social, and environmental responsibilities. In Proceedings of the FabLearn Europe 2019 Conference, Oulu, Finland. ACM. https://doi.org/10.1145/3335055.3335069

Rajanen, M., \& Rajanen, D. (2020, October). Instructional Storyboard Outcomes of a Co-creation Workshop for Safety Culture in Digital Fabrication. INTERACT No 3. University of Oulu, Finland. Retrieved from https://interact.oulu.fi/interact

Rheingold, H. (2008). Using Participatory Media and Public Voice to Encourage Civic Engagement. Civic life online: Learning how digital media can engage youth (pp. 97-118). The MIT Press, Cambridge, Massachusetts.

Sanders, E.B.N. (2003). From User-Centered to Participatory Design Approaches. Design and the social sciences (18-25). Taylor \& Francis, London.

Schunk, D.H. (2012). Learning theories an educational perspective (6th edition). Pearson.

Sellers, R. (2014). A professional culture of safety - The influence, measurement and development of organisational safety culture. Proceedings of the ISASI Seminar (pp. 13-16). Adelaide, Australia.

Short, D.B., Sirinterlikci, A., Badger, P., \& Artieri, B. (2015). Environmental, health, and safety issues in rapid prototyping. Rapid Prototyping Journal, 21(1), 105-110.

Väisänen, A.J., Hyttinen, M., Ylönen, S., \& Alonen, L. (2018). Occupational exposure to gaseous and particulate contaminants originating from additive manufacturing of liquid, powdered and filament plastic materials and related post-processes. Journal of Occupational and Environmental Hygiene, 16(3), 258-271.

Walsh, L. (2015). The Visual Rhetoric of Climate Change. Wiley Interdisciplinary Reviews: Climate Change, 6(4), 361-368.

Zhou, W., Whyte, J., \& Sacks, R. (2012, March). Construction safety and digital design: A review. Automation in Construction, 22, 102-111. 